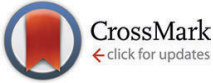

Cite this: Phys. Chem. Chem. Phys., 2015, 17, 20597

Received 4th May 2015 Accepted 6th July 2015

DOI: $10.1039 / c 5 c p 02587 g$

www.rsc.org/pccp

\title{
Luminescence and fine structure correlation in ZnO permeated porous silicon nanocomposites
}

\author{
D. Gallach, ${ }^{\star a}$ A. Muñoz-Noval, ${ }^{\text {bc }}$ V. Torres-Costa ${ }^{\text {ad }}$ and M. Manso-Silván ${ }^{a}$
}

\begin{abstract}
Nanocomposites formed by porous silicon (PS) and zinc oxide ( $\mathrm{ZnO}$ ) have potential for applications in optoelectronic devices. However, understanding the distribution of both materials in the nanocomposite, and especially the fine structure of the synthesized $\mathrm{ZnO}$ crystals, is key for future device fabrication. This study focuses on the advanced characterization of a range of PS-ZnO nanocomposites by using photonand ion-based techniques, such as X-ray absorption spectroscopy (XAS) and elastic backscattering spectroscopy (EBS), respectively. PS substrates formed by the electrochemical etching of $\mathrm{p}^{+}$-type Si are used as host material for the sol-gel nucleation of $\mathrm{ZnO}$ nanoparticles. Different properties are induced by annealing in air at temperatures ranging from $200{ }^{\circ} \mathrm{C}$ to $800{ }^{\circ} \mathrm{C}$. Results show that wurtzite $\mathrm{ZnO}$ nanoparticles form only at temperatures above $200{ }^{\circ} \mathrm{C}$, coexisting with Si quantum dots (QDs) inside a PS matrix. Increasing the annealing temperature leads to structural and distribution changes that affect the electronic and local structure of the samples changing their luminescence. Temperatures around $800{ }^{\circ} \mathrm{C}$ activate the formation of a new zinc silicate phase and transform PS into an amorphous silicon oxide $\left(\mathrm{SiO}_{x}, x \approx 2\right)$ matrix with a noticeably reduced presence of Si QDs. Thus, these changes affect dramatically the emission from these nanocomposites and their potential applications.
\end{abstract}

\section{Introduction}

The study of the composites obtained from porous silicon (PS) and zinc oxide $(\mathrm{ZnO})$ is an active field of research, especially since white photoluminescence was obtained from this system. ${ }^{1-3}$ This feature has attracted much attention due to its potential applications in solid-state white-light sources (SSWLS) compatible with integrated circuit (IC) technology. ${ }^{2,4}$ The origin of this white luminescence is the combination of two tunable materials whose emission covers the whole visible range as a result of the combined action of OD Si structures and ZnO. Thus, the PS-ZnO system is a particular type of $\mathrm{Si}-\mathrm{ZnO}$ composite, which covers also Si nanowires with transparent conducting ZnO used in field-emission applications. ${ }^{5-7}$ Another system that can be compared with the previous one after annealing in open air is silica-ZnO, although $\mathrm{ZnO}$ preparations in silicas cannot bear luminescence contributions from Si QDs. Such silica-ZnO composites have been prepared principally by wet routes $^{8}$ or by multilayer reactive magnetron sputtering. ${ }^{9}$

\footnotetext{
${ }^{a}$ Universidad Autónoma de Madrid, Facultad de Ciencias, Departamento de Física Aplicada e Instituto Nicolás Cabrera, Cantoblanco, 28049 Madrid, Spain. E-mail: dario.gallach@uam.es

${ }^{b}$ Spanish CRG, European Synchrotron Radiation Facility, Grenoble 38000, France

${ }^{c}$ Instituto de Ciencia de Materiales de Madrid-ICMM/CSIC, Cantoblanco,

Madrid E-28049, Spain

${ }^{d}$ Centro de Micro-Análisis de Materiales (CMAM),

Universidad Autónoma de Madrid, Cantoblanco, 28049 Madrid, Spain
}

On the one hand, PS exhibits strong, efficient red-orange luminescence at room temperature caused by the Si band-gap widening. ${ }^{10}$ In fact, electron confinement is induced in $\mathrm{Si}$ quantum dots (QDs) formed during the electrochemical etching process. ${ }^{11}$ The shape, size and lattice parameters of these $\mathrm{Si}$ nanocrystals embedded in PS has been studied previously by transmission electron microscopy (TEM). ${ }^{12,13}$ Particularly, the Si QDs size can be related with the PS photoluminescence emission using theoretical models developed for small semiconductor crystallites, ${ }^{14}$ and more specifically, for indirect band-gap QDs. ${ }^{15}$ Once exposed to the atmosphere, QDs remain inside a porous silica matrix $\left(\mathrm{SiO}_{x}, x \approx 2\right)$ with a high surface-to-volume ratio, ${ }^{16,17}$ which optimizes their optical coupling.

On the other hand, nanostructured $\mathrm{ZnO}$ presents a photoluminescence emission characterized by a strong UV band, as a result of exciton recombinations, and a blue-green emission, due to the presence of characteristic intrinsic defects. ${ }^{18} \mathrm{How}^{-}$ ever, fabrication processes affect directly the formation and concentration of these defects and delicate optimizations are required to modulate PS-ZnO photoemission. Relevantly, such optimization requires a detailed knowledge of the $\mathrm{ZnO}$ local structure, which has been previously investigated by X-ray absorption spectroscopy (XAS) in $\mathrm{ZnO}$ nanowires and nanoparticles. $^{19-21}$

Different approaches have been followed to deposit $\mathrm{ZnO}$ on PS or nucleate it inside PS such as pulsed laser deposition, ${ }^{1}$ magnetron sputtering, ${ }^{3,4}$ thermal spray ${ }^{22}$ or sol-gel spin-coating. ${ }^{23-25}$ 
Relevantly, the sol-gel technique has been described to produce proper nanocomposites with adjustable optoelectronic properties, since low surface tension $\mathrm{ZnO}$ precursors are able to permeate easily the PS with precise $\mathrm{Zn}^{2+}$ concentrations. ${ }^{26}$ In this case, the in-depth composition and structure should be studied in detail in view of the intrinsic heterogeneity associated with a permeabilitydependent process that is supposed to lead to a diffusion gradient of $\mathrm{ZnO}$ nanocrystals within the PS matrix. In this sense, Rutherford backscattering spectroscopy (RBS) has been previously used to characterize $\mathrm{ZnO}$ films ${ }^{27}$ and nanowires. ${ }^{28}$ At particular energies, elastic backscattering spectroscopy (EBS), allows increasing the sensitivity of particular elements (usually below $Z=20$ ) depending on the incident ion and angular configuration.

Annealing processes play a critical role in the formation of PS-ZnO structures for whichever compositing technique used. This is particularly the case for the sol-gel composites, since condensation takes place at room temperature giving rise to amorphous structures with abundant adsorbed organic species. A post permeation annealing treatment is thus required to promote transformation into $\mathrm{ZnO}$ crystallites. ${ }^{29}$ However, controlling the annealing temperature and the oxygen partial pressure during the synthesis process is essential since luminescence from these nanocomposites will depend on both the PS oxidation ${ }^{30}$ (changing the number of QDs present in PS as well as their band-gap energy) and the point defect concentration in $\mathrm{ZnO}^{31}$

This study aims at contributing to the understanding of the effect of most common annealing processes applied to PS-ZnO nanocomposites (that is, atmospheric annealing) on the global structure and composition as well as on the local structure of $\mathrm{ZnO}$ crystallites. The study focuses on annealing temperatures between $200{ }^{\circ} \mathrm{C}$ and $800{ }^{\circ} \mathrm{C}$, where substantial structural changes occur. To trace these changes, both conventional and advanced characterization techniques, such as RBS and XAS, have been used in conditions adapted to the measurement of nanomaterials in porous solid matrices. Understanding how the fine structure of these nanocomposites changes is a first step required to optimizing the different luminescence lines that may allow the design of devices with tunable light emission for future applications in solid state white-light sources.

\section{Experimental}

\subsection{Sample preparation}

Porous silicon (PS) layers were formed by the electrochemical anodization of $\mathrm{p}^{+}$-type (B-doped), low-resistivity $(0.01<\rho<$ $0.02 \Omega \mathrm{cm}),(100) \mathrm{Si}$ wafers in a HF (48 wt\%): EtOH solution ( $1: 2$ in volume). Before electrochemical etching, an $\mathrm{Al}$ contact was deposited at the back-side of the wafer by electron beam evaporation. To produce a suitable ohmic junction, the contact was annealed for 10 minutes at $450{ }^{\circ} \mathrm{C}$ by rapid thermal processing in an $\mathrm{N}_{2}$ atmosphere. The electrochemical process was carried out on a Si exposed area of $1.23 \pm 0.04 \mathrm{~cm}^{2}$ without illumination in a three-electrode cell at room temperature applying a constant current density of $80 \mathrm{~mA} \mathrm{~cm}{ }^{-2}$ for $30 \mathrm{~s}$ resulting in $1.5 \pm 0.3 \mu \mathrm{m}$ thick micro-porous structures.

Zinc oxide $(\mathrm{ZnO})$ nanocrystals were synthesized using a solgel spin-coating technique with slight modifications with respect to previously described routes. ${ }^{32}$ For this study, a $0.2 \mathrm{M}$ solution of zinc acetate dihydrate $\left(\mathrm{Zn}\left(\mathrm{CH}_{3} \mathrm{COO}\right)_{2} \cdot 2\left(\mathrm{H}_{2} \mathrm{O}\right), \geq 98 \%\right)$ diluted in absolute ethanol and monoethanolamine (MEA, with [MEA] = $\left[\mathrm{Zn}^{2+}\right]$ ) was prepared and stirred for 10 hours at $60{ }^{\circ} \mathrm{C}$ under reflux until a transparent sol was obtained. After aging, $50 \mu \mathrm{L}$ of this solution were deposited by spin-coating at $2500 \mathrm{rpm}$ during $30 \mathrm{~s}$ over PS. After room temperature condensation, the composites were annealed in a furnace in presence of air at different temperatures between $200{ }^{\circ} \mathrm{C}$ and $800{ }^{\circ} \mathrm{C}$ for 1 hour. The so formed PS-ZnO composites were labeled according to annealing temperature.

\subsection{Characterization techniques}

The morphology of the samples was studied by electron microscopy using a Philips XL-40 FEG Field-Emission Scanning Electron Microscope (FESEM) operated at $10 \mathrm{kV}$ using its throughthe-lens (TLD) detector. The cross-sectional images shown were obtained without any previous metallization.

Evolution of the crystalline structure upon annealing was determined using a Siemens D5000 HR diffractometer in the grazing-incidence X-ray diffraction configuration (GIXD) using $\mathrm{Cu}-\mathrm{K}_{\alpha}$ radiation $(\lambda=1.54 \AA)$. In order to increase the signal from the layer, the analysis was performed at a fixed angle of $0.5^{\circ}$ from $2 \theta=15^{\circ}$ to $2 \theta=70^{\circ}$ with increments of $\Delta \theta=0.04^{\circ}$ (accumulation time of $10 \mathrm{~s}$ ). The crystallite size was calculated using the Scherrer formula ${ }^{33}$ with the spherical particle approximation $D(h k l)=0.9 \lambda /\left(B_{(2 \theta)} \cos \theta\right)$ where $D(h k l)$ is the average grain size, $\lambda$ the X-ray wavelength, $B_{(2 \theta)}$ the full width at half maximum of the peak and $\theta$ its diffraction angle.

The elastic (non-Rutherford) backscattering spectrometry (EBS) technique was useful to study in-detail the in-depth composition. Due to a possible higher surface oxidation after annealing, the analysis was performed at oxygen resonant energies using a $3.035 \mathrm{MeV}$ helium $\left({ }^{4} \mathrm{He}^{+}\right)$ion beam. Backscattered He ions were detected using a surface barrier blind detector with an active area of $50 \mathrm{~mm}^{2}$, placed at a scattering angle of $\theta=170.4^{\circ}$ from the probe beam. Each data set was obtained depositing a charge of $20 \mu \mathrm{C}$, which corresponds to a particle density of $5.49 \times 10^{11}$ part sr. Beam current was stabilized at $17 \pm 2 \mathrm{nA}$. Data sets were fitted using SIMNRA 6.05 software $^{34}$ (the oxygen non-Rutherford cross-section used was from Cheng et al. $1993^{35}$ ).

Extended X-ray absorption fine structure (EXAFS) was used to study the $\mathrm{Zn}$ local structure of the $\mathrm{ZnO}$ nanoparticles ( $\mathrm{Zn}$ K-edge at $9.659 \mathrm{keV})$. The experiments were performed at the BM-25A beamline (5-35 keV) placed at the European Synchrotron Radiation Facility (ESRF). The fluorescence signal was registered with a 13-element $\mathrm{Si}(\mathrm{Li})$ detector from an e2v Scientific Instruments with the sample placed at $45^{\circ}$. During the measurements, a metallic thin film was used to set and calibrate the energy incoming from the monochromator. Each sample was compared with a pure $\mathrm{ZnO}$ 
powder sample. All data sets were processed by the Demeter software pack (v0.9.20). ${ }^{36}$

Photoluminescence (PL) was measured using a fluorimeter (Aminco Bowman series 2) operating with a $150 \mathrm{~W}$ continuouswave Xe lamp. Samples were excited with wavelengths between 350 and $400 \mathrm{~nm}$ in order to excite the different energy levels formed in the nanocomposite. Signal was recorded using a photomultiplier tube detector polarized at $500 \mathrm{~V}$. The emission scan was performed between 475 and $675 \mathrm{~nm}$, avoiding the second harmonic diffraction peak from the excitation wavelength. The PL response from the samples was also observed directly by fluorescence microscopy using an IX81 Olympus inverted microscope linked to a digital camera DP72 controlled by cell ${ }^{\mathrm{D}}$ software. The excitation source of this device is a $100 \mathrm{~W}$ $\mathrm{Hg}$ lamp operating at stabilized direct current, suitable for UV fluorescence.

\subsection{Supplementary information}

In this section, we explain the model used for EXAFS analysis. The number of guessing variables $(N)$ available for fitting is given by the Nyquist criterion $(N=2 \Delta k \Delta R / \pi)$. Assuming that EXAFS is ideally packed with information, our data allows the use of $N=11$ variables. However, the number of variables was kept under this value for a more consistent model. In order to keep $N$ as low as possible, a first shell was modelled as 4 atoms placed at $2.01 \AA$ and a second shell as $12 \mathrm{Zn}$ atoms at $3.23 \AA$. This approximation is valid since the bond distance resolution $(r=\pi / 2 \Delta k$ ) for this data set is $0.3 \AA$, which is higher than the resolution of the theoretical model. Fittings to these functions were made between 1 and $3.5 \AA$ in the real space using single scattering paths. To improve the reliability of the results, paths larger than the fitting window have been included (up to $5 \AA$ ). Fig. 5(a) shows how these paths tend to adjust the experimental data between 3.5 and $4 \AA$ showing consistency for this model. Multiple scattering paths would require different mean-square disorders to take into account the different lengths and number of $\mathrm{O}$ and $\mathrm{Zn}$ atoms involved. However, there is no information available in the data to resolve such an amount of variables, and combining them in a global scattering variable produces distorted models. For this reason, they were not taken into account as there is no statistical improvement.

\section{Results and discussion}

Fig. 1 shows cross-sectional images of PS-ZnO samples annealed at $600{ }^{\circ} \mathrm{C}$ (a) and $800{ }^{\circ} \mathrm{C}$ (b). Both samples show a $\sim 1.5 \mu \mathrm{m}$ thick PS layer where $\mathrm{ZnO}$ has permeated the columnar structure to form the nanocomposite. Fig. 1(a) reveals that PS columns propagate during etching along the [100] direction as expected from the etching of highly-doped $\mathrm{p}^{+}$-type (100) $\mathrm{Si}$ wafers. $^{37}$ The size of $\mathrm{ZnO}$ nanoparticles formed inside the PS structure is limited by the pore diameter. Moreover, the distribution of $\mathrm{ZnO}$ nanoparticles along the pore is homogeneous. Fig. 1(b) shows the cross-section of a sample annealed at $800{ }^{\circ} \mathrm{C}$. In this case, the PS-ZnO morphology dramatically changes and the original

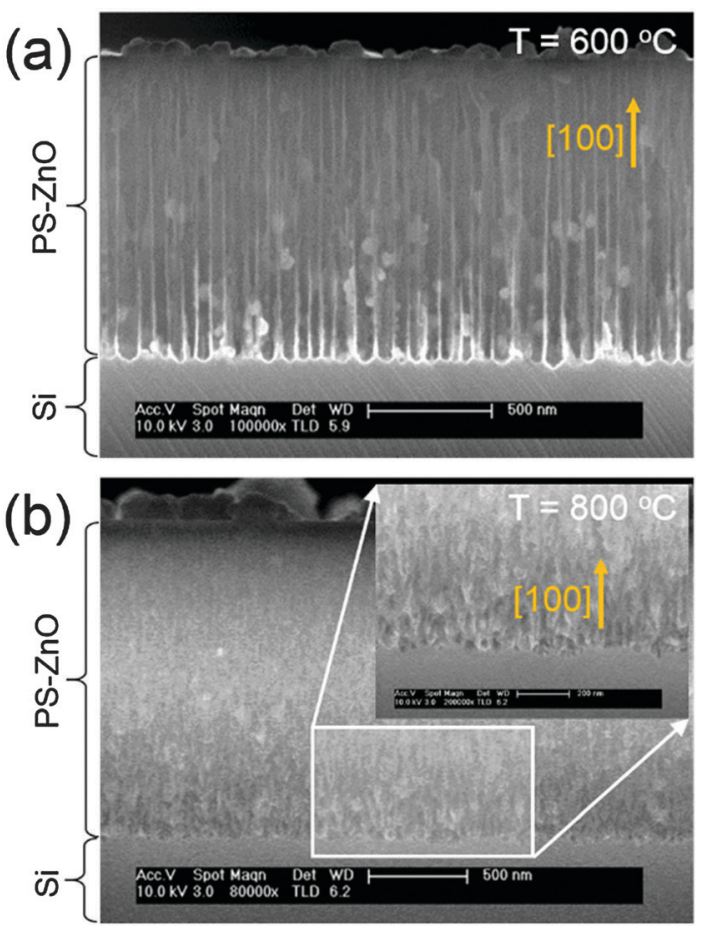

Fig. 1 Cross-sectional FESEM images of the samples annealed at $600{ }^{\circ} \mathrm{C}$ (a) and $800^{\circ} \mathrm{C}(\mathrm{b})$

columnar structure becomes a homogeneous matrix where $\mathrm{ZnO}$ nanocrystals are hardly distinguished. In addition, both figures show larger $\mathrm{ZnO}$ crystals formed at the surface, where no constrains for crystal growth are induced by pore walls. It is worth taking into account that as-prepared PS has a very large internal surface covered by highly reactive $\mathrm{Si}-\mathrm{H}$ bonds that is rapidly oxidized when exposed to the atmosphere. ${ }^{16,38}$ Thus, the incorporation of $\mathrm{O}$ atoms forms silica, increasing the PS volume. This process is enhanced when PS is annealed at high temperatures, which is clearly noticed in the dramatic changes observed in the sample annealed at $800{ }^{\circ} \mathrm{C}$. Specifically in this sample, both layer thickness and pore walls became larger compared to the sample annealed at $600{ }^{\circ} \mathrm{C}$. The original columnar structure of the pore along the (100) direction appears blurred and expanded (as seen in detail on the graph inset).

The X-ray diffractograms obtained from PS-ZnO samples annealed between $200{ }^{\circ} \mathrm{C}$ and $800{ }^{\circ} \mathrm{C}$ are shown in Fig. 2. The PS-ZnO annealed at $200{ }^{\circ} \mathrm{C}$ shows no distinguishable $\mathrm{ZnO}$ peaks due to the absence of long-range order in the first formation stages. However, a sharp peak centered at $56.14^{\circ}$ corresponding to $\mathrm{Si}(311)$ reflections can be identified. Its particular peak shape has been reported earlier ${ }^{39}$ and ascribed to the presence of non-uniform lattice distortions due to highly tensioned Si QDs inside the PS matrix. ZnO characteristic peaks appear around $2 \theta=35^{\circ}$ when the annealing step is carried out at $400{ }^{\circ} \mathrm{C}$. These peaks correspond to the (100), (002) and (101) planes from the most common hexagonal wurtzite structure ( $P 6_{3} m c$ space group) with $a=b=3.25 \AA, c=5.21 \AA$ (ICDD No. $361451)$. In addition, the $\mathrm{Si}(311)$ peak has been notably reduced 


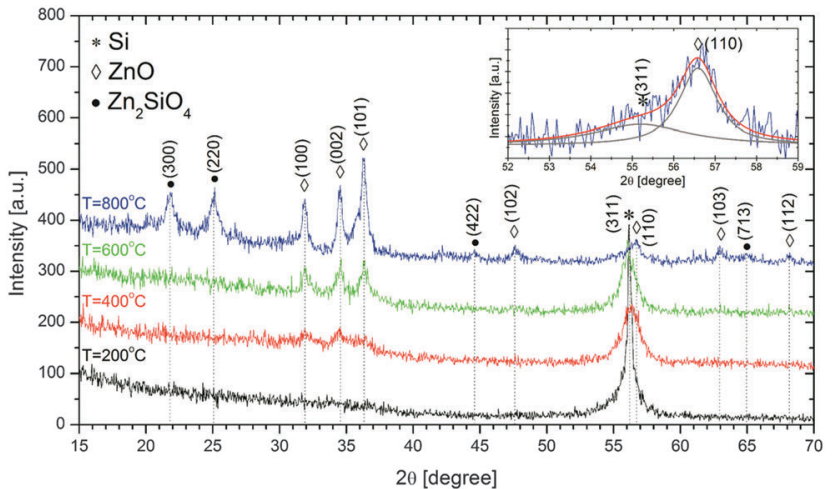

Fig. 2 GIXD patterns from PS-ZnO samples annealed between 200 and $800{ }^{\circ} \mathrm{C}$. The inset shows the deconvolution of the peak centered on $2 \theta=56^{\circ}$ at $800^{\circ} \mathrm{C}$

as a result of the PS oxidation induced by the annealing step in the presence of oxygen. The sample annealed at $600{ }^{\circ} \mathrm{C}$ indicates the same behavior but in this case the $\mathrm{ZnO}$ peaks are sharper, suggesting an increased long-range order. At the highest annealing temperature considered $\left(800{ }^{\circ} \mathrm{C}\right)$ new peaks are observed, which can be attributed to the activation of new $\mathrm{Zn}$ silicate phases $\left(\alpha-\mathrm{Zn}_{2} \mathrm{SiO}_{4}\right.$, ICDD No. 067235), as previously reported at temperatures around $900{ }^{\circ} \mathrm{C} .{ }^{40}$ Such formation of new phases may have a critical effect on the pore morphology modification described in the FESEM characterization for the particular samples annealed at $800{ }^{\circ} \mathrm{C}$. Another particular annealing effect at this temperature is that the (311) Si diffraction peak is hardly distinguishable (see inset graph in Fig. 2) due to the high oxidation of the PS matrix. ZnO crystallite size was calculated by the Scherrer formula resulting in values of 12,16 and $20 \mathrm{~nm}$ for the samples annealed at 400,600 and $800{ }^{\circ} \mathrm{C}$, respectively, revealing the improvement of $\mathrm{ZnO}$ crystallinity with higher annealing temperatures.

In order to determine the homogeneity of the Zn distribution along the porous network, an in-depth elemental composition profile was obtained by EBS at oxygen resonant energy (3035 keV). Fig. 3 presents the measured spectra and the fittings performed on the PS-ZnO samples annealed at temperatures between $200{ }^{\circ} \mathrm{C}$ and $800{ }^{\circ} \mathrm{C}$. The signal due to the $\mathrm{Zn}(\alpha, \alpha) \mathrm{Zn}$ interaction begins at $2.4 \mathrm{MeV}$ (corresponding to surface atoms) and is present through all the lower energies, confirming the presence of $\mathrm{Zn}$ atoms inside the PS pores. Compositions resulting from the fittings of $26 \times 10^{4}$ atomic monolayers to these spectra are shown in Table 1, where two atomic concentration values are reported: one evaluated at the first $100 \mathrm{~nm}$ surface layer and another evaluated at the last $100 \mathrm{~nm}$ layer (i.e. no backscattered He ions were detected from the bulk Si substrate). The signal from Si starts at $1.72 \mathrm{MeV}$, which corresponds well to surface atoms, demonstrating that no continuous $\mathrm{ZnO}$ surface layer has been formed. As seen in Table 1, the concentration of Si atoms in the sample annealed at $200{ }^{\circ} \mathrm{C}$ is higher due to less PS oxidation (around 38 at\%). When the temperature is increased to the range $400{ }^{\circ} \mathrm{C} \geq T \geq$ $800{ }^{\circ} \mathrm{C}$, oxygen composition increases up to $62-63 \%$, leading to $\mathrm{a}[\mathrm{Si}] /[\mathrm{O}]$ ratio of 0.5 , that is, close to that corresponding to $\mathrm{SiO}_{2}$.

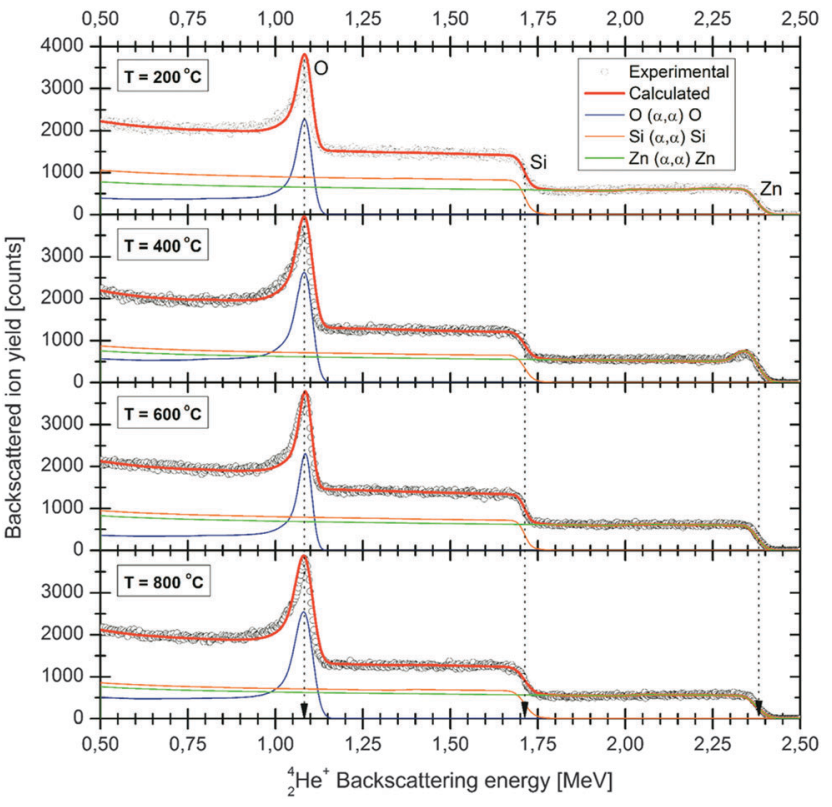

Fig. 3 EBS results for the samples annealed between 200 and $800{ }^{\circ} \mathrm{C}$ (hollow dots - experimental data, continuous line - fitted spectra) with individual contributions of $\mathrm{Zn}, \mathrm{O}$ and $\mathrm{Si}$ to each fitting.

Table 1 Atomic concentrations obtained from the EBS fittings of the samples annealed between $200{ }^{\circ} \mathrm{C}$ and $800{ }^{\circ} \mathrm{C}$ at the surface (first $100 \mathrm{~nm}$ layer) and at the bottom of the pores (last $100 \mathrm{~nm}$ layer). Experimental errors in parenthesis

\begin{tabular}{|c|c|c|c|c|c|c|}
\hline \multirow[b]{2}{*}{$\begin{array}{l}\text { Temperature } \\
\left({ }^{\circ} \mathrm{C}\right)(10)\end{array}$} & \multicolumn{3}{|c|}{$\underline{\text { Surface layer }(100 \mathrm{~nm})}$} & \multicolumn{3}{|c|}{ Bottom layer $(100 \mathrm{~nm})$} \\
\hline & $\begin{array}{l}\mathrm{Zn} \\
\text { at\% (0.5) }\end{array}$ & $\begin{array}{l}\mathrm{O} \\
\text { at\% (5) }\end{array}$ & $\begin{array}{l}\mathrm{Si} \\
\text { at\% (4) }\end{array}$ & $\begin{array}{l}\mathrm{Zn} \\
\text { at\% (0.5) }\end{array}$ & $\begin{array}{l}\mathrm{O} \\
\text { at\% (5) }\end{array}$ & $\begin{array}{l}\mathrm{Si} \\
\text { at\% (4) }\end{array}$ \\
\hline 200 & 5.7 & 56 & 38 & 4.0 & 56 & 40 \\
\hline 400 & 6.4 & 62 & 32 & 3.8 & 59 & 37 \\
\hline 600 & 5.6 & 62 & 33 & 2.6 & 60 & 37 \\
\hline 800 & 5.2 & 65 & 30 & 3.5 & 64 & 33 \\
\hline
\end{tabular}

However, the combined $\mathrm{Si}$ and $\mathrm{Zn}$ concentrations compared to $\mathrm{O}$ indicate an excess of non-oxidized $\mathrm{Si}$, which is explained by the presence of the Si QDs observed by GIXD. In the case of the sample annealed at $800{ }^{\circ} \mathrm{C}$, the trend of the atomic concentrations is in agreement (especially in the surface estimation) with the formation of an $\alpha-\mathrm{Zn}_{2} \mathrm{SiO}_{4}$ phase, since the stoichiometry becomes closer to that of the $\mathrm{ZnO}-\mathrm{SiO}_{2}$ derived compound. In all cases, the concentration of $\mathrm{Zn}$ is higher on the surface than inside the sample, which indicates the presence of an in-depth diffusion gradient.

XANES spectra of the PS-ZnO nanocomposites annealed at the different temperatures are shown in Fig. 4 . The white line main resonances of the Zn K-edge (labelled A, B and C in Fig. 4) are related to electron transitions from occupied $\mathrm{Zn}-1 \mathrm{~s}$ to unoccupied $\mathrm{Zn}-4 \mathrm{p}$ states along the main axes of the $\mathrm{ZnO}$ unit cell. It is widely accepted that the relative height of the main peaks in the white line spectra can be related to the existence of vacancies that are evidenced by polarization effects in crystalline structures. ${ }^{41}$ In this case, $\mathrm{ZnO}$ nucleates randomly giving rise to a polycrystalline structure which does not allow obtaining such 


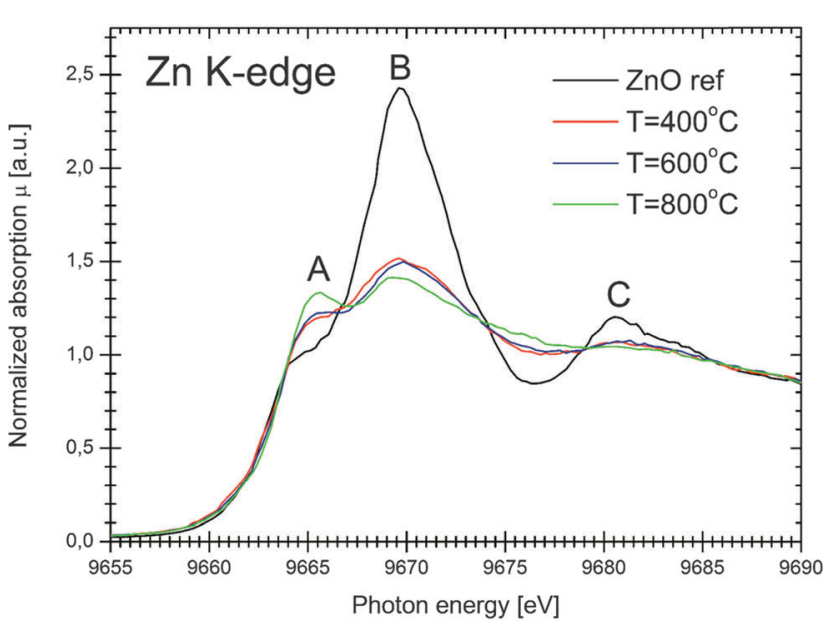

Fig. 4 XANES spectra of the PS-ZnO nanocomposites and a bulk $\mathrm{ZnO}$ reference. PS-ZnO samples have been annealed at 400,600 and $800{ }^{\circ} \mathrm{C}$ in atmospheric conditions.

information. Thus, special attention is paid to the main peak (B), since it is the most sensitive to the local deficiency or excess of $O$ in the absorber vicinity. Additionally, XANES can also account for other properties, like interatomic distances. ${ }^{42}$

Comparing the spectra corresponding to PS-ZnO samples annealed at different temperatures with the $\mathrm{ZnO}$ reference, remarkable differences can be outlined. Comparisons are restricted to samples containing crystalline $\mathrm{ZnO}$ phases (i.e. annealed from 400 to $800{ }^{\circ} \mathrm{C}$ ). The oxidation state is in all cases clearly the one corresponding to that of the $\mathrm{ZnO}$ reference, as derived from the absence of relative shift of the absorption edge in Fig. 4. However, the three resonances A, B and C are very different due to the modification of the scattering paths in the $\mathrm{Zn}$ atom vicinity. It is noticeable that the intensity of features A and B increase in all samples in contrast to peak C, whose intensity is slightly reduced. The comparison of experimental and $a b$ initio theoretical spectra indicates that these changes of the spectral shape are mainly determined by local structure defects. ${ }^{21}$ In fact, theoretical studies of nanocrystalline $\mathrm{ZnO}$ show that oxygen vacancies $\left(\mathrm{V}_{\mathrm{O}}\right)$ are the principal candidates to produce these spectral modifications. ${ }^{20}$ Specifically, the increase in amplitude in $A$ can be attributed to the combined effect of $V_{O}$ and the relaxation induced displacement of the central atom in the coordination shell. Indeed, $\mathrm{V}_{\mathrm{O}}$ in $\mathrm{ZnO}$ crystals are thermodynamically favored, even when the annealing is performed in an oxygen rich atmosphere, for temperatures above $473 \mathrm{~K} .{ }^{31}$ For the sample annealed at $800{ }^{\circ} \mathrm{C}$, an increase of pre-peak A is noticeable while peaks $\mathrm{B}$ and $\mathrm{C}$ are considerably reduced. This can be explained by the structural changes in the local coordination caused by the formation of the new phase $\alpha-\mathrm{Zn}_{2} \mathrm{SiO}_{4}$.

The information obtained from XANES has been complemented with a detailed analysis of the EXAFS signal. Fig. 5(a) shows the $\chi(k)$ data obtained from fluorescence EXAFS. A sample of wurtzite $\mathrm{ZnO}$ powder was measured to compare results, showing characteristic peaks denoted by $\mathrm{W}_{1}$ and $\mathrm{W}_{2}$. PS-ZnO nanocomposites annealed between 400 and $800{ }^{\circ} \mathrm{C}$ show the same $\chi(k)$ oscillatory behavior as the wurtzite reference, supporting the GIXD results. However, changes in A, B and C features (see labels on graph) indicate particular structural differences, especially for the sample annealed at $800{ }^{\circ} \mathrm{C}$, where zinc silicates have been identified. To study these changes, a FEFF theoretical model was developed starting from a $P 6_{3} m c$ ZnO structure with $a=b=3.2495 \AA$ and $c=5.2069 \AA$. The scattering path calculations obtained from this structure induce two main contributions to the Fourier transform at 1.5 and $3.5 \AA$, as identified in Fig. 5(b). The first one is produced by the interaction of the scattering electron with the tetrahedron formed by $3 \mathrm{O}$ atoms at a distance of $2.14 \AA$ and another at $1.79 \AA$ from the $\mathrm{Zn}$ absorbing atom. The second one is constituted by Zn atoms, 6 placed at $3.21 \AA$ and 6 at $3.25 \AA$ (both shell structures can be schematically seen in the inset in Fig. 5(b)).

Although the spectra in Fig. 5(b) are all very similar, the corresponding peak of the second shell of $\mathrm{Zn}$ atoms varies in amplitude. This change can be attributed to a change in the degeneracy of the coordination number $(N)$ or to the shell mean-square disorder $\left(\sigma^{2}\right)$. However, since the nanoparticle size $(\sim \mathrm{nm})$ and the coordination shell size $(\sim \AA ̊ \AA)$ differ by an order of magnitude, it makes sense to consider that most $\mathrm{Zn}$
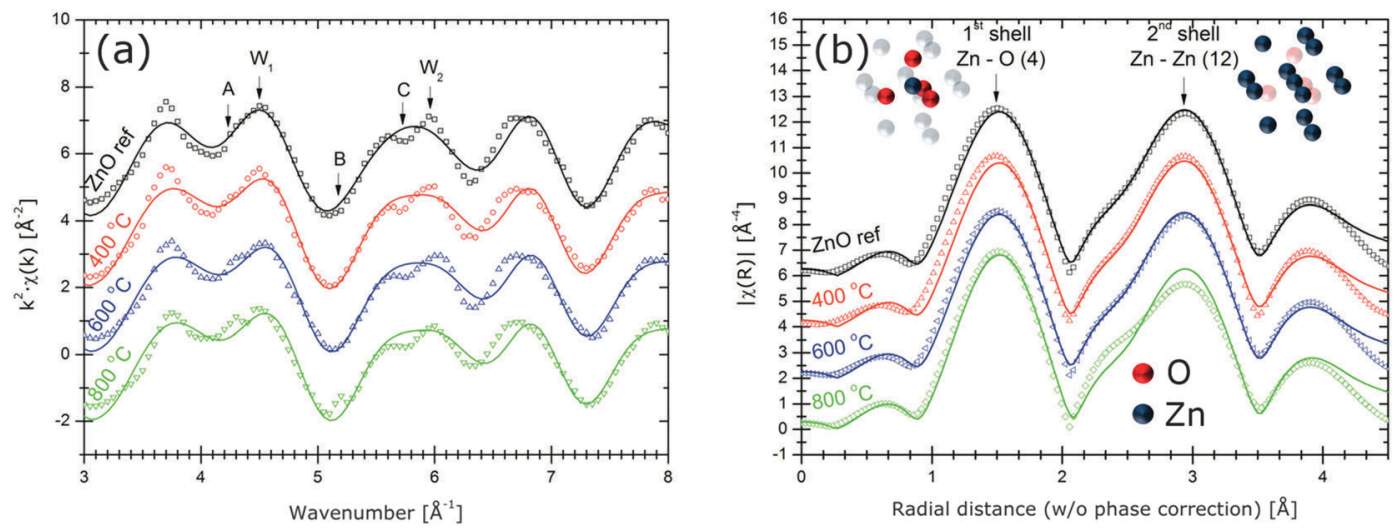

Fig. $5 k^{2} \cdot \chi(k)$ (a) and its Fourier transform (b) for the $\mathrm{ZnO}$ reference and the samples annealed between 400 and $800{ }^{\circ} \mathrm{C}$. Experimental data are represented with hollow symbols while the fit to the data is shown with continuous lines. FT is not phase-corrected. An inset to (b) shows the atoms in the structure contributing to the shell. 
Table 2 Results from the fittings to the 1st and 2nd shells. PS-ZnO samples are labelled according to the temperature used during the annealing process

\begin{tabular}{|c|c|c|c|c|c|c|}
\hline \multirow[b]{2}{*}{ Sample } & \multicolumn{3}{|c|}{ Zn-O (1st shell) } & \multicolumn{3}{|c|}{ Zn-Zn (2nd shell) } \\
\hline & $N$ & $R / \AA$ & $\sigma_{\mathrm{o}}^{2}\left(\times 10^{-4}\right) / \AA^{2}$ & $N$ & $R / \AA$ & $\sigma_{\mathrm{Zn}}^{2}\left(\times 10^{-4}\right) / \AA^{2}$ \\
\hline $\mathrm{ZnO}$ & 4 & $2.01 \pm 0.01$ & $25 \pm 8$ & 12 & $3.23 \pm 0.02$ & $65 \pm 10$ \\
\hline 400 & 4 & $2.01 \pm 0.02$ & $27 \pm 10$ & 12 & $3.23 \pm 0.02$ & $87 \pm 8$ \\
\hline 600 & 4 & $2.01 \pm 0.03$ & $33 \pm 12$ & 12 & $3.23 \pm 0.03$ & $94 \pm 10$ \\
\hline 800 & 4 & $2.01 \pm 0.03$ & $35 \pm 15$ & 12 & $3.23 \pm 0.03$ & $97 \pm 11$ \\
\hline
\end{tabular}

atoms are fully coordinated and thus, variations due to the presence of point defects or lattice distortions can be derived from the parameter $\sigma^{2}$.

Numerical results from the fittings can be found in Table 2 . In the case of the sample annealed at $400{ }^{\circ} \mathrm{C}$, the first oxygen coordination shell mean-square disorder $\left(\sigma_{\mathrm{o}}{ }^{2}\right)$ is close to the value obtained for the reference. However, $\sigma_{\mathrm{o}}{ }^{2}$ increases approximately by $40 \%$ in the case of the samples annealed at $600{ }^{\circ} \mathrm{C}$ and $800{ }^{\circ} \mathrm{C}$. This contrasts with the GIXD results that showed an improvement in the long-range order, but can be compatible with a significant presence of non-ordered $\mathrm{V}_{\mathrm{O}}$ in this shell. In the case of the second coordination shell formed by $\mathrm{Zn}$ atoms, the mean-square disorder $\sigma_{\mathrm{Zn}}{ }^{2}$ for the PS-ZnO composites show variations between $40 \%$ and $50 \%$. However, this shell is also affected by $\mathrm{Zn}-\mathrm{O}$ single-scattering paths beyond the fitting $R$-range that affect directly the value of $\sigma_{\mathrm{Zn}}{ }^{2}$ as well as the presence of $\mathrm{V}_{\mathrm{O}}$ and oxygen antisite $\left(\mathrm{O}_{\mathrm{Zn}}\right)$ defects. Green emission from PS-ZnO nanocomposites has been attributed earlier to $\mathrm{O}_{\mathrm{zn}},{ }^{43}$ especially when the oxygen partial pressure is increased $\left(0.5 \cdot \mathrm{O}_{2}(\mathrm{~g})+\mathrm{V}_{\mathrm{Zn}}=\mathrm{O}_{\mathrm{Zn}},\left[\mathrm{O}_{\mathrm{Zn}}\right] \propto\left(p_{\mathrm{O}_{2}}\right)^{1 / 2}\left[\mathrm{~V}_{\mathrm{Zn}}\right]\right)$ and it should not be overlooked. As data are obtained from a Zn K-edge, the nearest $\mathrm{O}_{\mathrm{Zn}}$ must be at least at the distance of the first $\mathrm{Zn}$ neighbor (3.21 $\AA$ if it is considered that the $\mathrm{O}$ atom stays in the same site as the $\mathrm{Zn}$ atom), having a minor contribution to the white line compared to the contribution of the four coordinated oxygen neighbors in the tetrahedron around the absorbing $\mathrm{Zn}$ atom (3 at $1.96 \AA$ and 1 at $2.01 \AA$ ). Therefore, $\mathrm{O}_{\mathrm{Zn}}$ must not be discarded when oxygen is present during the annealing process of PS-ZnO nanocomposites. Considering this, feature C (Fig. 4) decreases with temperature, probably indicating that the distance between the absorbing $\mathrm{Zn}$ atoms and the first oxygen neighbors

(a)

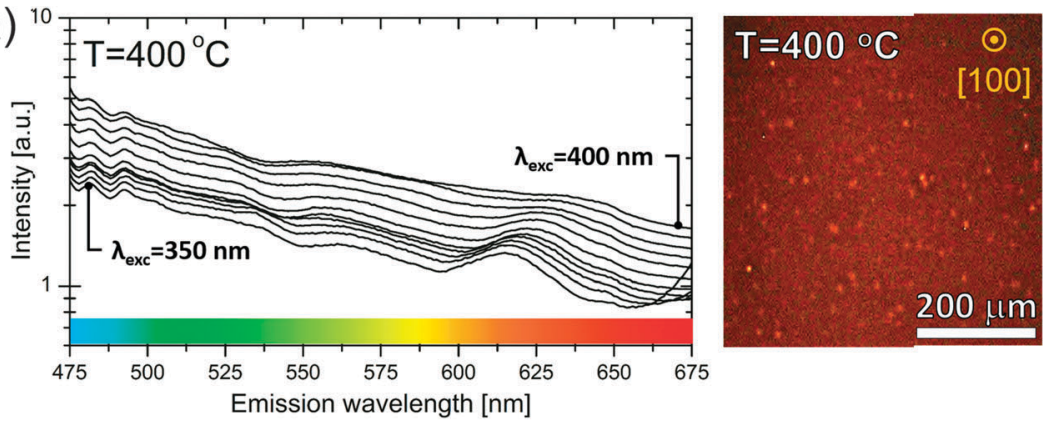

(b)

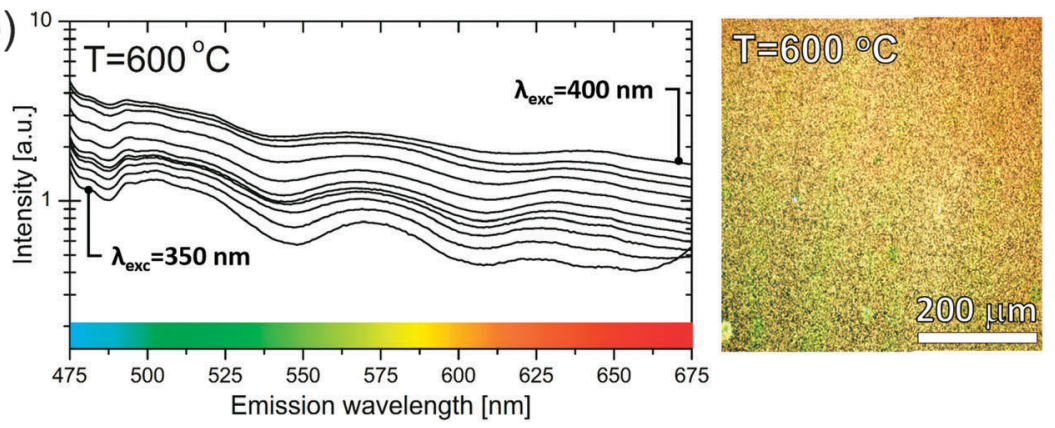

(c)

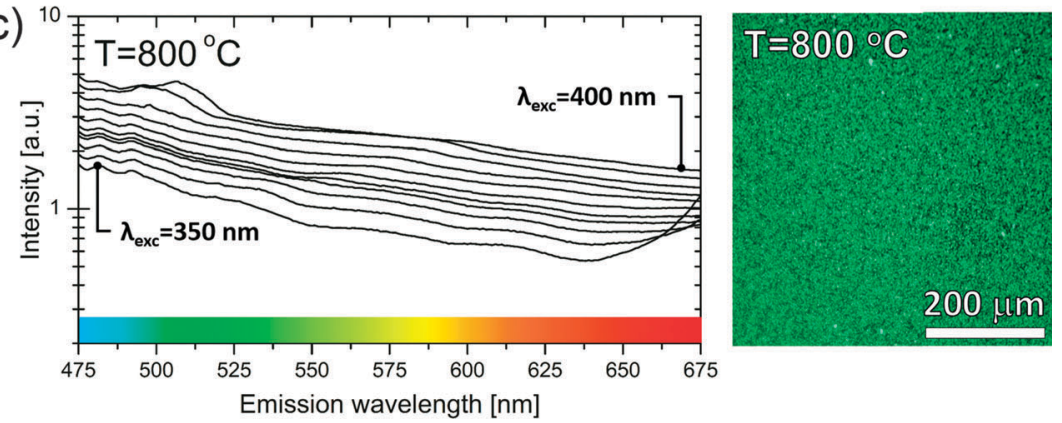

Fig. $6 \mathrm{PL}$ measurements and fluorescence microscopy images taken from the samples annealed at temperatures between $400{ }^{\circ} \mathrm{C}$ and $800{ }^{\circ} \mathrm{C}$. Note that the features observed at $481 \mathrm{~nm}$ and $492 \mathrm{~nm}$ correspond to discrete lamp emission lines. 
$\left(d_{\mathrm{Zn}-\mathrm{O}}\right)$ slightly increases. This is in consonance with the increasing uncertainty in the interatomic distance $R$ (Table 2). If these sites were occupied by oxygen atoms $\left(\mathrm{O}^{2-}\right.$ with larger ionic radius instead of $\mathrm{Zn}^{2+}$ with shorter ionic radius) the distance $d_{\mathrm{Zn}-\mathrm{O}}$ would tend to decrease by the compression induced by a larger atom replacing the $\mathrm{Zn}$ position. Summarizing, the results from XAS measurements suggest that oxygen vacancies are more likely to happen than oxygen antisites, although both can be present in the structure.

As previously reported, these nanocomposites are able to produce white-light through the combination of red-orange emission from PS and blue-green emission from $\mathrm{ZnO}^{1-3}$ In order to observe the effects on luminescence of the processing history of the sample, PL measurements combined with fluorescence microscopy have been used to perform an optical characterization. Fig. 6(a-c) show the PL spectra and nonfiltered images of PS-ZnO composites annealed at 400, 600 and $800{ }^{\circ} \mathrm{C}$, respectively. The sample annealed at $400{ }^{\circ} \mathrm{C}$ shows a broad PL peak centered at $618 \mathrm{~nm}$ corresponding to PS characteristic orange-red emission. ${ }^{16}$ As seen in GIXD measurements, $\mathrm{ZnO}$ crystals are formed around that temperature, but no significant blue-green emission is observed. This result is supported by its optical fluorescence image. As previously mentioned, the PS PL peak can be related to the Si QDs within PS. ${ }^{12}$ Thus, the Si QDs' average size has been calculated, resulting in $19 \pm 2 \AA$ using the suggested model for the exciton quantum confinement in QDs of indirect band-gap materials.

At $600{ }^{\circ} \mathrm{C}$, in coincidence with the XANES pre-peak increase (feature A in Fig. 4), luminescence from the sample shows a yellowish color. This result is supported by the coexistence of $\mathrm{Si}$ and $\mathrm{ZnO}$ nanocrystals in the PS-ZnO composite around that temperature, as demonstrated by GIXD. Furthermore, PL spectra show that this yellowish emission is the combination of three main emission bands centered at 510, 572 and $625 \mathrm{~nm}$. The band centered at $625 \mathrm{~nm}$ corresponds to PS but the other bands are directly related to $\mathrm{ZnO}$. Specifically, the broad blue-green (almost yellow) emission can be attributed to $\mathrm{O}_{\mathrm{Zn}}$ and $\mathrm{V}_{\mathrm{O}}$ intrinsic defects, respectively, ${ }^{3,44}$ which is in agreement with the XANES and EXAFS results. Nevertheless, the emission around $510 \mathrm{~nm}$ may be constituted partly by luminescence originating in silica formed in the PS structure, whose presence is more evident at this temperature, as shown by EBS.

Finally, the PL spectra and an optical fluorescence image of a sample annealed at $800{ }^{\circ} \mathrm{C}$ are shown. The emission observed through the fluorescence microscope shows a greenish color attributed to point defects on $\mathrm{ZnO}$ nanocrystals and the characteristic luminescence from $\alpha-\mathrm{Zn}_{2} \mathrm{SiO}_{4}{ }^{40}$ The detailed study of the PL spectra show a blue-green band when the samples are irradiated with $\lambda_{\text {exc }}>$ $490 \mathrm{~nm}$. This result is remarkable and indicates that a different luminescence mechanism is taking place, merging contributions from silica, $\mathrm{ZnO}$ intrinsic defects (at least $\mathrm{V}_{\mathrm{O}}$ and $\mathrm{O}_{\mathrm{Zn}}$ ) and $\alpha-\mathrm{Zn}_{2} \mathrm{SiO}_{4}$.

\section{Conclusions}

The annealing temperature plays an important role in the physical properties of PS-ZnO nanocomposites, affecting their luminescence, which is determined by a critical balance between Si QDs and defects in ZnO. Crystallinity and the concentration of point defects can be controlled by means of temperature annealing.

Specifically, electron microscopy shows PS-ZnO nanocomposites formed by a columnar PS matrix and $\mathrm{ZnO}$ nanoparticles at relatively low processing temperatures $\left(200{ }^{\circ} \mathrm{C}<\right.$ $T<600{ }^{\circ} \mathrm{C}$ ). However, the PS structure becomes an amorphous $\mathrm{SiO}_{x}$ matrix when the sample is annealed at $800{ }^{\circ} \mathrm{C}$. X-Ray diffraction showed that the formation of wurtzite $\mathrm{ZnO}$ starts at temperatures above $200{ }^{\circ} \mathrm{C}$. PS QDs coexist with ZnO nanocrystals for higher temperatures below $800{ }^{\circ} \mathrm{C}$, when a new phase appears $\left(\alpha-\mathrm{Zn}_{2} \mathrm{SiO}_{4}\right)$. At this temperature, the presence of Si QDs has been remarkably reduced. EBS indicates that ZnO permeates the pores establishing a concentration gradient along the pore. Stoichiometry indicates that annealing in presence of oxygen leads to the matrix oxidation in the form of $\mathrm{SiO}_{2}$. Changes in the XANES spectra indicate that the most probable point defects found in this structure are oxygen vacancies $\left(\mathrm{V}_{\mathrm{O}}\right)$ but it does not discard the presence of a much lower concentration of antisite oxygen atoms $\left(\mathrm{O}_{\mathrm{Zn}}\right)$ in the $\mathrm{ZnO}$ structure. EXAFS supports this conclusion, showing an increase in the local structural disorder in the first atomic layer that can be attributed to these defects. Fluorescence microscopy shows a yellowish emission at $600{ }^{\circ} \mathrm{C}$, when Si QDs' red emission coexists with the blue-green emission from oxygen vacancies in $\mathrm{ZnO}$. This technique shows the dramatic changes induced in the composites annealed at $800{ }^{\circ} \mathrm{C}$, where no PS-induced emission is observed although a strong green luminescence from zinc silicates remains the main emitting source.

In summary, the emission of PS-ZnO nanocomposites obtained by sequential electrochemical-sol-gel processing can be controlled by varying the annealing temperature. This must be taken into account in order to obtain the desired luminescence when envisaging particular optoelectronic applications.

\section{Acknowledgements}

The authors would like to thank the Sidi-UAM for their technical support as well as CMAM and the BM25A Spanish CRG beamline for allocating us for ion and X-ray beamtime, respectively. Funding through grant MAT2013-46572-C2-1-R from Ministerio de Economía y Competitividad is greatly appreciated.

\section{References}

1 B. Zhao, Q. S. Li, H. X. Qi and N. Zhang, Chin. Phys. Lett., 2006, 23, 1299.

2 R. G. Singh, F. Singh, D. Kanjilal, V. Agarwal and R. M. Mehra, J. Phys. D: Appl. Phys., 2009, 42, 062002.

3 E. Kayahan, J. Lumin., 2010, 130, 1295.

4 D. Dimova-Malinovska and M. Nikolaeva, Vacuum, 2002, 69, 227.

5 N. S. Das, D. Banerjee and K. K. Chattopadhyay, J. Mater. Sci., 2013, 48, 750. 
6 Y.-M. Chang, M.-C. Liu, P.-H. Kao, C.-M. Lin, H.-Y. Lee and J.-Y. Juang, ACS Appl. Mater. Interfaces, 2012, 4, 1411.

7 V. S. Kale, R. R. Prabhakar, S. S. Pramana, M. Rao, C.-H. Sow, K. B. Jinesh and S. G. Mhaisalkar, Phys. Chem. Chem. Phys., 2012, 14, 4614.

8 W. H. Zhang, J. L. Shi, L. Z. Wang and D. S. Yan, Chem. Mater., 2000, 12, 1408.

9 J.-H. Lim, K. H. Lee and D. C. Lim, J. Korean Phys. Soc., 2011, 58, 1664.

10 L. T. Canham, Appl. Phys. Lett., 1990, 57, 1046.

11 A. G. Cullis and L. T. Canham, Nature, 1991, 353, 335.

12 R. J. Martin-Palma, L. Pascual, P. Herrero and J. M. MartinezDuart, Appl. Phys. Lett., 2002, 81, 25.

13 R. J. Martin-Palma, L. Pascual, A. R. Landa-Canovas, P. Herrero and J. M. Martinez-Duart, Mater. Sci. Eng., C, 2006, 26, 830.

14 L. E. Brus, J. Chem. Phys., 1984, 80, 4403.

15 T. Takagahara and K. Takeda, Phys. Rev. B: Condens. Matter, 1992, 46, 15578.

16 O. Bisi, S. Ossicini and L. Pavesi, Surf. Sci. Rep., 2000, 38, 1.

17 M. V. Wolkin, J. Jorne, P. M. Fauchet, G. Allan and C. Delerue, Phys. Rev. Lett., 1999, 82, 197.

18 A. Janotti and C. G. Van de Walle, Rep. Prog. Phys., 2009, 72, 126501.

19 E. S. Jeong, H. J. Yu, S. W. Han, S. J. An, J. Yoo, Y. J. Kim and G. C. Yi, J. Korean Phys. Soc., 2008, 53, 461.

20 A. Kuzmin, S. Larcheri and F. Rocca, Zn K-edge XANES in nanocrystalline ZnO, Riga, Latvia, 2007.

21 A. Kuzmin and J. Chaboy, IUCrJ, 2014, 1, 571.

22 H. Elhouichet and M. Oueslati, Mater. Sci. Eng., B, 2001, 79, 27.

23 C. Shaoqiang, Z. Jian, F. Xiao, W. Xiaohua, L. laiqiang, S. Yanling, X. Qingsong, W. Chang, Z. Jianzhong and Z. Ziqiang, Appl. Surf. Sci., 2005, 241, 384.

24 R. G. Singh, F. Singh, V. Agarwal and R. M. Mehra, J. Phys. D: Appl. Phys., 2007, 40, 3090.

25 H. Cai, H. L. Shen, Y. G. Yin, L. F. Lu, J. C. Shen and Z. X. Tang, J. Phys. Chem. Solids, 2009, 70, 967.
26 Y. M. Huang, Q.-l. Ma and B.-g. Zhai, J. Lumin., 2013, 138, 157.

27 C. Bundesmann, N. Ashkenov, M. Schubert, D. Spemann, T. Butz, E. M. Kaidashev, M. Lorenz and M. Grundmann, Appl. Phys. Lett., 2003, 83, 1974.

28 J. Karamdel, C. F. Dee, K. G. Saw, B. Varghese, C. H. Sow, I. Ahmad and B. Y. Majlis, J. Alloys Compd., 2012, 512, 68.

29 L. Znaidi, Mater. Sci. Eng., B, 2010, 174, 18.

30 J. Salonen, V. P. Lehto and E. Laine, Appl. Surf. Sci., 1997, 120, 191.

31 C. Drouilly, J. M. Krafft, F. Averseng, S. Casale, D. BazerBachi, C. Chizallet, V. Lecocq, H. Vezin, H. Lauron-Pernot and G. Costentin, J. Phys. Chem. C, 2012, 116, 21297.

32 N. Kumar, K. Neera and R. M. Mehra, J. Lumin., 2007, 126, 784.

33 B. D. Cullity, Elements of X-Ray Diffraction, Prentice-Hall, 3rd edn, 2001.

34 M. Mayer, Application of Accelerators in Research and Industry, Pts 1 and 2, 1999, vol. 475, p. 541.

35 C. Huan-Sheng, S. Hao, T. Jia-Yong and Y. Fu-Jia, J. Lumin., 2013, 138, 157.

36 B. Ravel and M. Newville, J. Synchrotron Radiat., 2005, 12, 537.

37 P. C. Searson and J. M. Macaulay, Nanotechnology, 1992, 3, 188.

38 M. J. Sailor, Porous Silicon in Practice: Preparation, Characterization and Applications, Wiley-VCH Verlag $\mathrm{GmbH} \& \mathrm{Co}$, 1st edn, 2012.

39 M. J. E. Pinèík, J. Barto, C. Falcony and M. Kuèera, Superficies Vacio, 1999, 9, 78.

40 R. G. Singh, F. Singh, R. M. Mehra, D. Kanjilal and V. Agarwal, Solid State Commun., 2011, 151, 701.

41 J. Haug, A. Chasse, M. Dubiel, C. Eisenschmidt, M. Khalid and P. Esquinazi, J. Appl. Phys., 2011, 110, 063507.

42 G. Bunker, Introduction to XAFS: A Practical Guide to X-Ray Absorption Spectroscopy, Cambridge University Press, 2010.

43 B. X. Lin, Z. X. Fu and Y. B. Jia, Appl. Phys. Lett., 2001, 79, 943.

44 D. Das and P. Mondal, RSC Adv., 2014, 4, 35735. 